\title{
DIAGNOSTIC PROCEDURES IN THYROID DISEASE
}

\author{
By Russell Fraser, M.D., F.R.C.P., D.P.M. \\ Reader in Medicine, Postgraduate Medical School, London
}

Various diagnostic aids may be used to supplement clinical investigation when either the patient is still only suspected of raised or lowered thyroid function, or when the pathology of his thyroid lump still remains in doubt. We shall consider in this paper, the various tests available for assessing the level of thyroid secretory activity; of these there are three main tests and at least three subsidiary indirect tests each with its own special usefulness and its limitations. Since the advent of radioiodine and also of improved techniques for the micro-chemical estimation of iodine, tests of iodine metabolism have tended to dominate this field, but they have not yet completely supplanted either the older B.M.R. or the various subsidiary tests. Space does not permit consideration of the uses of needle biopsy of the thyroid or of thyroid scanning after radioiodine, procedures which are especially useful for the diagnosis of thyroid nodules and of suspected lymphadenoid goitre. The finding of a raised serum gamma-globulin is also a useful confirmatory sign of a lymphadenoid goitre.

\section{Tests of Total Thyroid Function}

\section{The Basal Metabolic Rate (B.M.R.)}

The oldest clinical measure of total thyroid function still provides the best index of the severity of a disorder of thyroid furrction, and estimates the effect of the thyroid hormone on body tissues. But as a measure of thyroid function it has some defects; firstly, there are other causes of an abnormal metabolic rate, secondly, it may be difficult to attain the basal state in a patient, and thirdly, we may err in our prediction of the normal B.M.R. to be expected with certain patients, i.e., with children or with very fat or very thin patients. But proper clinical examination should reveal any other disease likely to lead to an abnormal B.M.R.; and with due precautions a truly basal state should be attainable in nearly all patients.

The B.M.R. is estimated from a measure of the oxygen consumed by the patient when he is
' basal' (i.e. both fasted for 12 hours and corsig' pletely resting). It is usually expressed as od percentage of the oxygen consumption expected for a healthy person of similar size, age, and sex. obtainable from standard tables. With goodel apparatus, the main problem is that of gettiog the patient in the completely resting state. Ondy careful expert technicians using one or two traini runs can achieve this with most patients without the help of sedation. This difficulty has even been reflected in the B.M.R. standards. The commondy used standards (Aub and Du Bois, 1917; Boothey et al., 1936) were derived from measurements made on the subject's first visit to the laborafory. Repeated B.M.R. estimations on the same sulyect have shown that the first two or three results to be higher than the level of values achieve thereafter (Vogelius, 1945). Robertson and Regd (1952) collected more truly basal standards from subjects who had had preliminary training vis $\$$ until duplicate readings were attained agreei $\overrightarrow{\mathrm{Bg}}$ within 5 per cent. These standards were found to lie about ro per cent. lower than the previo画 and still commonly used standards. With skilled technician the same procedure can be used clinically, and the results should be estimated against these standards; which show a normgl range of + or -13 per cent.

An alternative procedure which uses the sange standards is the estimation of the sleeping B.M.R. (Rapport, 1951; Fraser and Nordin, 1955). Bn this procedure the patient is given sedation which induces sleep but avoids the risks of anaesthesia; by giving either intravenously a slowly-acting barbiturate such as pentobarbitone sodium, or orally three separate hourly doses of amylo barbitone. To be certain that the patient is basan, the estimation must be made with the patieft sleeping. The only real disadvantage of this procedure is the subsequent drowsiness of the patient for the rest of the day; which can be minimized by a subsequent oral dose of a ba룽 biturate antagonist (Ibbertson et al., 1957). The standards for the sleeping B.M.R. are the same 


\section{THE 3 MAIN TESTS FOR (Myxoedema (untreated) \\ Thyrotoxicosis(untreated)}

(BY S. D. Ranges]

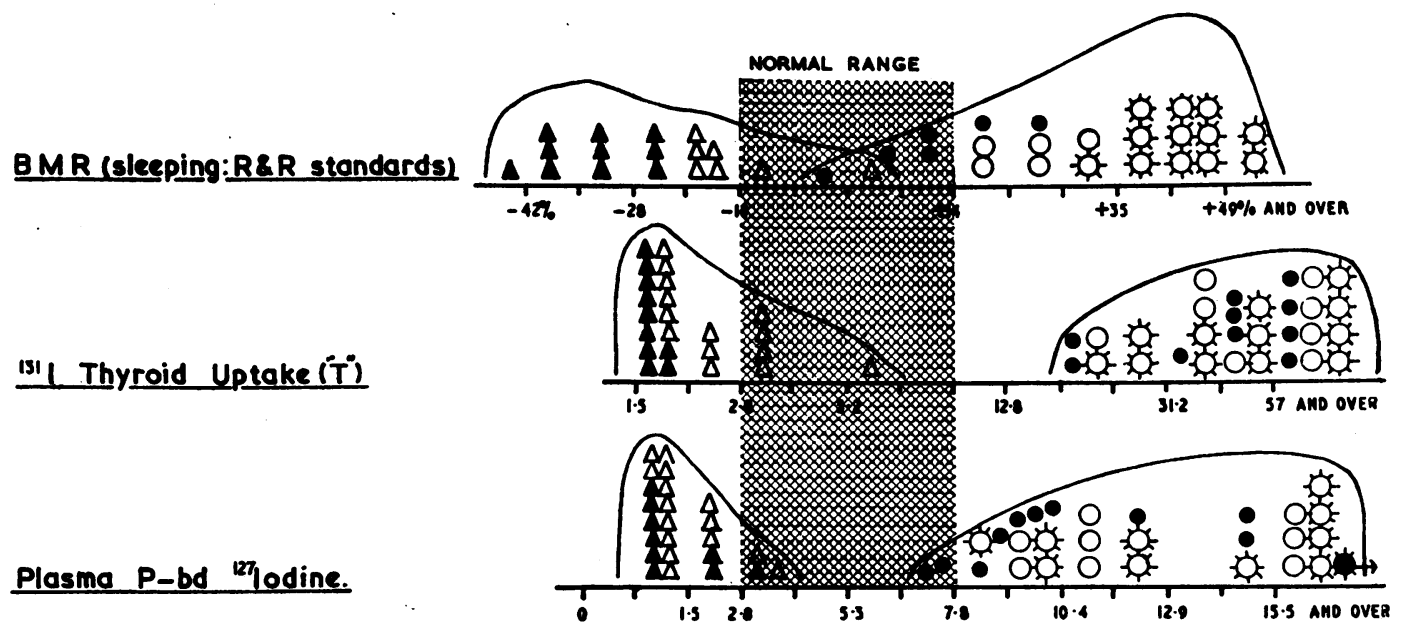

Myxoedema

Thyrotoxicosis

- severe 10

he severe 12 th CRISIS

$1 \cdot 10 \cdot 95$

$\triangle$ MILO is

O moderate -

- Mico 10

FIG. 1.-Results of three main tests in proved myxoedema and thyrotoxicosis. Each scale is matched in standard-deviation ranges of normals in order to compare tests' sensitivities. Nearly all B.M.R.s were recorded sleeping, and their results are shown as percentage of appropriate mean Robertson and Reid (1952) standards. (From Fraser (1956), Lancet.)

those for the properly trained and basal B.M.R., as Nordin and Fraser found. Further Benedict and Hendry (1921) found the B.M.R. of the sleeping adolescent to lie 7 to ro per cent. below the then prevailing untrained standards; i.e., in the same range as that found in the trained basal state (Robertson and Reid, 1952; Shock and Soley, 1939; Bierring, 1931).

A narrower range of normal B.M.R. values which would permit a more sensitive estimation of deviations therefrom, would be attainable if the B.M.R. standards could also be corrected for abnormal body builds, as well as for size, age and sex. Most standards use surface area to estimate body size; which is perhaps the best basis except in children where height may be better, or in fat and thin patients. For the latter, we should have some additional correction incorporated to allow for the abnormal proportion of their body size which is metabolically active tissue, i.e., for their proportion as lean body mass (Miller and Blyth, 1953; Behnke, 1953; Kleiber, 1956). Over a wide range of animals the relation to size is surprisingly consistent if the weight formula is used $\left(B=3 W^{*}\right)$, (Kleiber, 1947).

\section{Radioiodine Tests}

These tests are capable of measuring the rate at which some phase of the body's iodine cycle is occurring and so of assessing thyroid cell activity. They cause minimal inconvenience to the patients and involve a smaller radiation hazard than many common X-ray diagnostic procedures. Their great advantage is their independence of the nervous state of the patient, and their disadvantage is their susceptibility to misinterpretation after certain drugs, and when the body's store of iodine is either depleted or over-filled.

After previous treatment to the thyroid or with drugs containing iodine or thyroid substance, or after depletion of the body's iodine stores by an abnormal diet or by a course of antithyroid drugs, these tests will reflect these circumstances as well as thyroid secretory activity. This disadvantage is not overcome by any variation in the type of radioiodine test, short of a 'supplemented 
radioiodine test' (see below). This is because radioiodine tests measure the thyroid turnover of iodine not in absolute units or micrograms, but in terms of the extracellular fluid's content of iodide. Suspicion of these sources of error may arise either from a history of recent drug administration, which should always be sought; or when an abnormal radioiodine result is found which does not seem compatible with the patient's previous clinical picture. Such suspicions should not arise in more than about ro per cent. of the patients tested, and then some of the special supplementary radioiodine tests mentioned below, or other tests of thyroid function, need to be done. These will confirm or refute this possibility that the radioiodine test is not simply reflecting thyroid secretory function, and also will measure thyroid function in the light of this suspicion.

${ }^{131}$ I of 8-day half-life is the usual form of radioiodine used; but if it is desired to repeat the test frequently, ${ }^{132}$ I of 2.4 -hour half-life can be used with one of the rapid types of technique. The dose is either given intravenously or orally on an empty stomach, and in either case rapidly mixes throughout the extracellular fluid. It is thence cleared at constant rates into both the thyroid and the urine, most of this being completed normally between 24 and 48 hours. Between the third and the twenty-fourth hour, the radioactivity in the thyroid begins to be secreted back into the plasma as thyroid hormone which circulates there bound to the plasma proteins. This simple theory provides an adequate basis for the interpretation of clinical tests.

Several types of radioiodine test are available, which vary in their convenience or in their accuracy. But all of which have approximately the same sensitivity in reflecting the rate of iodine transfer and so of thyroid function (Pochin, 1950; Myant, 1952; Keating et al., 1950; Fraser et al., 1953; Wayne, 1954; Rall, 1956). Except after certain drugs or when the stores of iodine are abnormal, it is safe to assume that the thyroid uptake and secretion rate are in equilibrium. All radioiodine tests are very sensitive to the increased thyroid function, and segregate the thyrotoxic group well away from the normal range, though some non-toxic hyperplastic goitres show similarly high uptakes. Severe or complete myxoedema is also fully distinguished but mild thyroid deficiency overlaps the normal range even more on the radioiodine test than on the other main tests of thyroid function. This is probably because thyroid failure leads to less conserving and storing of iodine in the body and so to an iodine deficiency. The rate of iodine transfer can be measured either 'at the uptake into the thyroid (Step I of the iodine cycle), which can be assessed either from urine measurements $\stackrel{0}{\mathscr{T}}$ from measurements at the neck, or at its ro appearance in the plasma as protein-boun radioiodine (Step $\mathrm{I}+$ Step 2 of the iodine cycle

Uptake measurements, whether from the urine of from neck measurements, are more sensitive and specific when they are based on two or mofe measurements from which can be derived a rae reflecting the thyroid clearance of iodide. Such rate measurements will then be independent of an abnormality of renal function. Single measures ments are however often used because of the simplicity; for clinical examination can usually detect any suspicion of renal disease. For the recognition of thyrotoxicosis, an early measur $\bar{\xi}$ ment, i.e., one done at any phase during the firs four to six hours, is most suitable. A late measure ment, i.e., one at or up to the 48 th hour, is besir. suited to the recognition of thyroid deficienceses for in partial thyroid deficiency the early uptakis may be normal or even rapid but it is then poorly retained in the thyroid. A common compromise for a simple routine test is the measurement of the 24-hour thyroid collection or uptake. The bes urine test involves collections in three periods (usually 0-8, 8-24 and 24-48 hours); these cand then be measured quickly and accurately, ant errors in collection are usually revealed fron oddities in the subdivision between the samp(⿻日木] The radioiodine content of this second collectopt period ( 8 to 24 hours) usually gives a good reflecto of thyroid uptake; and from the three periods a ' $\mathrm{T}$ ' index of thyroid uptake can be calculateg

$$
\begin{gathered}
(0-8 \mathrm{hr} . \%) \times 100 \\
(8-24 \mathrm{hr} . \%) \times(0-48 \mathrm{hr} . \%) \\
\text { normal values }=2.8-\mathrm{I} 3 .
\end{gathered}
$$

This ' $T$ ' gives a good approximation to the thyroid clearance rate, expressed as a percentage of extracellular fluid cleared per hour (Fraser et al 1953). It is, of course, really an index of extra renal disposal rate, and so even in complete thyroid failure its value falls only to about $x-2$. When errors of urine collection are suspected, i.e $\frac{\mathrm{O}}{3}$ in up to 10 per cent. of tests, another repeaf radioiodine test based on neck : measurements must be given. Another simple but less precise index of thyroid clearance may be derived b measuring the neck/thigh ratio at an early phast such as two hours (Pochin, 1950). This howevero requires special apparatus and the values obtaine are not in absolute units but depend on the apparatus used. With slightly more elaboration the thyroid clearance may be measured directlo during the first or second hour preferably afte零 intravenous doses, by various procedures based of neck measurements made in association wit $\mathbb{P}$ either thigh, plasma, or urine measurements to 
index the falling extracellular concentration from which the clearance is occurring (Pochin, 1950; Foote and Maclagan, 195I; Coenegracht and Fraser, 1955).

Plasma tests, the remaining type of test, are based on the measurement in single plasma samples of the radioactivity which has reached the hormonal fraction, i.e., the protein-bound ${ }^{131} \mathrm{I}$ (P.B. $\left.{ }^{131} \mathrm{I}\right)$; the samples are usually taken at 48 or 72 hours. Such clearly index the rate at which the radioiodine passes through the thyroid, but need a sensitive counter and a larger dose of radioiodine than uptake tests. For this reason they are not usually suited to the recognition of thyroid failure but are well suited to the recognition of increased thyroid function. Along with all radioiodine tests, they are however subject to the general limitations already noted. They are convenient in requiring only one sample which can easily be measured in a distant laboratory, but have little other advantage over the types of test based on uptake measurements. The results may be expressed either simply as a concentration of P.B. ${ }^{131}$ I (Goodwin et al., I95I; Ingbar et al., 1954) as a 'conversion-ratio,' the ratio of the P.B. ${ }^{131}$ I to iodide-131 I in the plasma (Sheline et al., 195I), or possibly more sensitively as a ratio of P.B. ${ }^{131}$ I to salivary iodide (Thode et al., 1954). This last procedure takes advantage of the fact that the iodide of the plasma is concentrated into the saliva, normally about thirty-fold; but this is not so important since the really critical measurement of this test is that of the plasma P.B. ${ }^{131} \mathrm{I}$. As most of the radioiodine in the plasma at 48 hours is hormonal, even the measurement of total plasma radioactivity gives a good simple index.

Interpretation of Results. Whatever type of test is used, the result is first to be interpreted as indicating either increased, decreased or normal thyroid cell activity. Wherever possible this should be done against the normal values of the district for the type of test used. Excluding the known iodine deficient areas, most urban areas give a similar normal range. A normal or low result in suspected hyperthyroidism is extremely rare, unless the previous iodine intake has been abnormal, and so this can usually exclude such a diagnosis. In perhaps ro per cent. of non-toxic goitres, a high uptake will be found; these are hyperplastic goitres, many of which are iodine deficient and some of which may have subclinical hyperthyroidism. A high result will usually be found at the conclusion of a course of antithyroid drugs, since these will have induced an iodine deficiency. In lymphadenoid goitres, all types of uptake may be found according to the stage of the disease. Subacute thyroiditis is characterized by absent thyroid uptake despite clinical evidence of normal or even increased thyroid secretion. The possibility of depressed uptakes due to concurrently administered drugs, especially iodides, antithyroid drugs, or thyroid extract must always be considered. Moderate hypopituitarism, without associated clinical signs of complete hypothyroidism, may have a normal thyroid uptake of radioiodine; as may the lesser degrees of primary thyroid failure. Some types of cretinism show a rapid transfer of radioiodine; this is due to incomplete organic binding of the iodine in the thyroid (McGirr and Hutchison, 1955; Stanbury et al., 1955). Immediately after sub-total thyroidectomy, radioiodine uptake is increased, probably from iodine deficiency. For approximately two months after radioiodine treatment, the uptake will be depressed due to temporary radiation effects. Where the clinical picture does not appear to accord with the radioiodine findings, the supplementary radioiodine tests mentioned below are indicated, to clarify whether these findings had reflected abnormal iodine stores.

\section{Supplemented Radioiodine Tests}

Additions to the sensitive radioiodine tests which can check on iodine deficiency or excess, are now available to overcome most of the limitations of these tests.

(i) Associated Chemical Measurements of Iodine. There is no simple procedure for estimating? chemically the body's iodide pool and thereby transforming the radioiodine uptake into absolute figures (Riggs, I952). However, a simple chemical measurement on urine can reveal excess iodide, but it is unreliable for detecting subnormal amounts of iodide and so for detecting iodine deficiency' (Fraser et al., 1953).

(ii) Drug Loading Tests. To distinguish high uptakes due to iodine deficiency; the iodinerepletion test and the triiodothyronine suppression test.

The iodide repletion test is based on the simple theory that an adequate period of iodide administration can correct an iodine deficiency, while a subsequent four weeks gap will permit elimination of the coincident iodide-flooding, so that the patient may then be retested free of any suspicion of iodine deficiency. The standard iodide load recommended is $10 \mathrm{mg}$. of potassium iodide (K.I.) given as a pill for 14 days, and the retesting. is done four weeks later. Burrell and Fraser (1957) have found this a valid way of distinguishing anxiety states or non-toxic goitres with high thyroid uptakes from thryotoxicosis; and also of discriminating between clinically-remitted and unremitted cases of thyrotoxicosis at the conclusion of a period of antithyroid drug treatment. 
The avid thyroid uptake of iodine deficiency is known to depend mainly on anterior pituitary stimulation, which itself arises from the consequent lowered thyroid secretion (Burrell and Fraser, 1957). The administration of normal or slightly supra-normal amounts of thyroid hormone should therefore suppress this avidity. The administration of similar amounts of thyroid hormone to thyrotoxic patients does not however suppress their avid radioiodine uptake; for whatever its basis it is not a lack of secreted thyroid hormone. This is the basis of the triiodothyronine suppression test which thus also distinguishes the avid thyroid uptake of thyrotoxicosis from that of iodine deficiency; the uptake in the supplemented test being suppressed both in normals and in the latter condition but not in thyrotoxicosis. In this test the patient is given $0.18 \mathrm{mg}$. of triiodothyronine daily for eight days and then given the final radioiodine test on the seventh day. Alternatively 6 to $9 \mathrm{gr}$. of thyroid extract may be given daily and the test given on the fourteenth day (Greer and Smith, I954; Werner and Spooner, I955; Perlmutter and Slater, 1955; Higgins and Fraser, 1957).

These tests are helpful for assessing unexpectedly high thyroid uptakes of doubtful clinical significance; and are particularly useful whenever a patient needs testing after a course of antithyroid drug treatment." While the iodiderepletion test is simple and reliable, it involves a delay of six weeks, which is rarely important with these doubtful cases; and it does correct the basic iodine deficiency which the other test leaves uncorrected. When a quick answer is needed and the patient is not seriously ill, the triiodothyronine test may be preferred.

(iii) Tests after thyroid stimulating hormone (T.S.H.). This offers a means of assessing whether a patient taking thyroid really needs to do so (the thyroid administration need not be stopped), and also of whether a thyroid deficiency is or is not dependent only upon pituitary failure. Lowered thyroid uptake not due to primary thyroid failure may be restored after administering TSH daily for one to five days, even though the patient is still taking thyroid.

Chemical Estimation of Protein-bound Iodine ( $\left.{ }^{127} \mathrm{I}\right)$.

This test measures mainly the concentration of thyroid hormone circulating in the plasma. Since it is technically difficult because it measures in micrograms and not in milligrams per $100 \mathrm{ml}$., the preceding tests are generally to be preferred. Its main usefulness is for the recognition of partial thyroid deficiency, and its use should probably be reserved for those cases suspected of such a disorder who do not show a clearly abnormal result on the preceding tests, and also for cases suspected of thyrotoxicosis factita. The latter is characterized by a high P.B. ${ }^{127} \mathrm{I}$, associate with a low ${ }^{131}$ I uptake.

The true normal range is probably 3.5 to $7 . \frac{2}{5}$ $\mu \mathrm{g} . / 100 \mathrm{ml}$., and of this $\mathrm{I}$ to $2 \mu \mathrm{g}$. is non-hormonal. and probably iodide. But the accuracy of the estimation is rarely better than $\pm \mathrm{I} \mu \mathrm{g} . / 100 \mathrm{mt}$ and is often poorer so that estimations on normats can easily fall outside the true normal range as reflected in the published normal ranges, somg of which start from 2.6 and some of which ris = to I $1.3 \mu \mathrm{g}$. per $100 \mathrm{ml}$. Values within I $\mu \mathrm{g}$. of the normal limits are therefore never certain indicators of abnormal thyroid function; and similarly some mild cases of thyrotoxicosis and also a few with thyroid deficiency are found to show normal valu骨 (Blackburn and Power, 1955; Bierwalters, 195 Fraser, 1956). Further sources of error to bo remembered are the low values which are found when the serum albumin is low or when the patient has received mercury, the slightly high values found in normal pregnancy, and the higto values which may persist for many months after the administration of organic iodine-containing drugs.

Subsidiary Indirect Tests

(i) Creatinuria is a feature of most thyrotgx $\overrightarrow{0}$ patients (Treusch et al., 1944) but also of severa other conditions involving muscular wast and is associated with raised serum creatine le For the recognition of thyrotoxicosis, it has beep superseded by the preceding tests.

(ii) Serum Cholesterol and Other Signs of Thyro\% Deficiency. The recognition of the minor grades of thyroid deficiency remains the Achilles heel of thyroid tests. Most cases of thyroid deficienç show a raised serum cholesterol level, and i demonstration is an important corroboration of the meaning of a low B.M.R. But low levels are net a diagnostic feature of thyrotoxicosis. With children suspected of myxoedema the X-rays can help by revealing epiphyseal dysgenesis which is specific sign of thyroid deficiency. Confirmation of the signs of myxoedema may also be had from the E.C.G. which in thyroid deficiency shows rather non-specific lowering of ' $T$ ' waves. When there is still doubt, a therapeutic trial with two weeks of thyroid extract, I g. per day may be given; and the deficient patient will then show over 20 per cent. lowering of serum cholestera level and a rise in the height of the ' $\mathrm{T}$ ' waves on the E.C.G.

We may conclude that the tests at present available can recognize all treatable thyrotoxicosis, and most treatable thyroid deficiency, provided tests are chosen which are appropriate to the patient's total clinical state.

Bibliography continued on page $32 \mathrm{I}$ 
size or vascularity may be more easily obtained. The treatment by these means of a retrosternal goitre which is already causing pressure symptoms, involves the careful use of repeated small doses of radioiodine to avoid the risk of oedema of the irradiated tissue in the days following the dose, and an increase in obstruction. For these reasons, radioiodine has only a limited use in reducing the size of ectopic thyroid deposits but may occasionally be of value.

\section{REFERENCES}

I. BLOMFIELD, G. W., JONES, J. C., MACGREGOR, A. G., MILLER, H., WAYNE, E. J., and WEETCH, R. S.' (1955), Brit. med. भ., ii, 1223.

2. CHAPMAN, E. M., and MALOOF, F. (1955), Medicine (Baltimore), 34, 26I

3. CLARK, D. E. (1955), F.A.M.A., 159, 1007.
4. COLIEZ, R., TUBIANA, M., DUTREIX, J. M., and LAUGIER, A. (1956), Bull. Cancer, 43, 218.

5. DUFFY, B. J., and FITZGERALD, P. J. (1950), f. clin. Endocr., 10, 1296 .

6. FRASER, R., ABBATT, J. D., and STEWART, F. S. (1954), Brit. F. Radiol., 29, 434.

7. HAHN, P. F. (1956), 'Therapeutic Use of Artificial Radioisotopes' (New York: John Wiley \& Sons, Inc.).

8. HAMILTON, J. G., and LAURENCE, J. H. (1952), f. clin. Invest., 21, 624 .

9. HERTZ, S., and ROBERTS, A. (1942), f. clin. Invest., 21,624 10. HILTON, G. (1956), Brit. F. Radiol., 29, 297.

11. MALOOF, F., VICKERY, A. L., and RAPP, B. (1956), f. clin. Endocr., 16, I.

12. POCHIN, E. E. (1957), 'Modern Trends in Endocrinology' (ed. Dr. H. Gardiner-Hill), in the press.

13. POCHIN, E. E., CUNNINGHAM, R. M., and HILTON, G. (1954), \%. clin. Endocr., 14, 1300.

14. POCHIN, E. E., and HALNAN, K. E. (1957), Metabolism., 6,49

15. RAWSON, R. W., RALL, J. E., and ROBBINS, J. (1953), Arch. intern. Med., 92, 299.

16. SIMPSON, C. L., HEMPELMANN, L. H., and FULLER, L. M. (1955), Radiology, 64, 840 .

\section{HOW TO GET THERE}

An Address Book for the Medical profession, showing how to reach the various Colleges, Societies, Institutes and Hospitals in or near London

New (Fourth) Edition: 1954

Price 2s. 6d. (2s. 10d., post free)

Published by the

FELLOWSHIP OF POSTGRADUATE MEDICINE

60 Portland Place, London, W.I

Continued from page 316-Russell Fraser, M.D., F.R.C.P., D.P.M.

\section{BIBLIOGRAPHY}

AUB, J. C., and DU BOIS, E. F. (1917), Arch. intern. Med., 19, 823. BEHNKE, A. R. (1953), Ann. N.Y. Acad. Sci., 56, 1095.

BEIERWALTES, W. H. (1956), Ann. intern. Med., 44, 40.

BENEDICT, F. G., and HENDRY :M. F. (1921), Boston med. surg. F., 184, 217.

BIERRING, E. (1931), 'The Standard Metabolism of Boys (7 to 18 years inclusive),' Levin and Munksgaard, Copenhagen.

BLACKBURN, C. M., and POWER, M. H. (1955), f. clin. Endocr., $15,1379$.

BOOTHBY, W. M., BERKSON, J., and DUNN, H. L. (1936), Amer. $\mathscr{f}$. Physiol., I16, 468.

BURRELL, C. D., and FRASER, R. (1957). Quart. F. Med. To be published.

COENEGRACHT, J., and FRASER, R. (1955), F. Endocr., 12, 185.

FOO'TE, J. B., and MACLAGAN, N. F. (195I), Lancet, i, 868.

FRASER, R. (1956), lbid., ii, 581.

FRASER, R., HOBSON, Q. J. G., ARNOTT, D. G., and EMERY, E. W. (1953), Quart. Э. Med., N.S., 22, 99.

FRASER, R., and NORDIN, B. E. C. (1955), Lancet, i, 532.

GOODWIN, J. F., MACGREGOR, A. G., MILLER, H., and WAYNE, E. J.' (195I), Quart. F. Med., 20, 353.

GREER, M. A., and SMITH, G. E. (1954), F. clin. Endocr., 14, 1374. HIGGINS, H. P., and FRASER, R. (1957). To be published.

IBBERTSON, K., JOPLIN, G., and FRASER, R. (1957), Brit. med. $\mathcal{F}$. In press.

INGBAR, S. H., FREINKEL, N., HOEPRICH, P. D., and ATHENS, J. W. (1954), F. clin. Invest., 33, 388.
KEATING, F. R., Jr., HAINES, S. F., POWER, M. H., and WILliAMS, M. M. D. (1950), f. clin. Endocr., 10, 1425. KLEIBER, M. (1947), Physiol. Rev., 27, 511.

KLEIBER, M. (1956), Ann. Rev. Physiol., 18, 35.

MILLER, A. T., and BLYTH ,C. S. (1953), J. appl. Physiol., 5, 311. MYANT, N. B. (1952), Brit. med. Bull., 8, 141.

McGIRR, E. M., and HUTCHISON, J. H. (1955), F. clin. Endocr. $15,668$.

PERLMUTTER, M., and SLATER, S. (1955), F. Amer. med. Ass., I58, 718.

POCHIN, E. E. (1950), Lancet, ii, 41 .

RALL, J. E. (1956), Amer. F. Med., 20, 719.

RAPPORT, R. L., CURTIS, G. M., and SIMCOX, S. J. (195I), F. clin. Endocr., $11,1549$.

RIGGS, D. S. (1952), Pharmacol. Rev., 4, 284.

ROBERTSON, J. D., and REID, D. D. (1952), Lancet, i, 940.

SHELINE, G. E., MOORE, M. C., KAPPAS, A., and CLARK, D. E. (1951), '. clin. Endocr., 11, 91.

SHOCK, N. W., and SOLEY, M. H. (1939), F. Nutr., 18, 143.

STANBURY, J. B., OHELA, K., and PITT-RIVERS, R. (1955), F. clin. Endocr., 15, 54 .

THODE, H. G., JAIMET, C. H., and KIRKWOOD, S. (1954), New Engl. \%. Med., 25I, 129.

TREUSCH, J. V., KEPLER, E. J., POWER, M. H., and HAINES, $\mathscr{f}$ S. F. (1944), Amer. F. med. Sci., 208, 310.

VOGELIUS, H. (1945), Acta med. scand., Suppl. 165.

WAYNE, E. J. (1954), Brit. med. F., i, 411 .

WERNER, S. C., and SPOONER, M. (1955), Bull. N.Y. Acad. Med., 31, 137 . 